\title{
Perianal Endometriosis: A Case Report and Our Clinical Experience.
}

\author{
Dr Meghraj Kundan ${ }^{1}$,Dr Anju Kumari ${ }^{2}$,Dr Prabhakar Krishna ${ }^{3}$,Dr Ashish ${ }^{4}$, \\ Dr Tarun Singh ${ }^{5}$,Dr Gaind Kumar Saurabh ${ }^{6}$ \\ ${ }^{I}$ Assistant Professor, Department Of General Surgery, VMMC And Safdarjung Hospital, New Delhi-29, India. \\ ${ }^{2}$ Post Graduate Student, Department Of OBS \& GYNAE, UCMS \& Guru Teg Bahadur Hospital, \\ Delhi-95, India. \\ ${ }^{3,4,5}$ Senior Resident, Department Of General Surgery, VMMC And Safdarjung Hospital, New Delh \\ ${ }^{6}$ Senior Resident, Department Of CTVS,AIIMS, New Delhi ,India.
}

\begin{abstract}
Endometriosis is a relatively common disease. Perianal endometriosis is a rarest condition, which occur frequently at episiotomy scar. We present a rare case of perianal endometriosis. A 37 year old female presents with perianal swelling with intermittent pain. Pain was not cyclical in nature. There was no discharge or bleeding from swelling. Patient had history of episiotomy. Perianal swelling was excised with wide margin and sent for biopsy. Biopsy report suggested perianal endometriosis.
\end{abstract}

Keywords: Biopsy, Episiotomy scar, female, Pain, Perianal endometriosis

\section{Introduction}

Endometriosis is defined as the presence of functional endometrial tissue in an anatomical location outside the uterus. ${ }^{1}$ Ectopic endometrial tissue is identified as endometrial glands and stromal tissue generally accompanied by hemosederin laden histiocytes. Endometriosis frequently involves the female reproductive system. The most common site for endometriosis is the ovary. Endometriosis may occur in the uterine ligaments, rectovaginal septum, fallopian tubes, recto sigmoid colon, ureter, bladder, umbilicus, inguinal and perianal regions. Endometriosis may occur rarely at scar site in the lower abdominal wall following operations on the uterus or fallopian tubes or episiotomy scar. ${ }^{2-10}$

Endometriosis may be asymptomatic or symptoms like subfertility, dysmenorrhea, dyspareunia or chronic pelvic pain may occur. Endometriosis associated with scar presents as a swelling or nodule, which may occur after few weeks to years following surgery. Swelling may be tender or occasional bleeding may present. Perianal endometriosis usually seen in episiotomy scar and may involve the septum between vagina and anal canal. Perianal endometriosis may present as tender swelling which may mimic like perianal abscess and may be treated as abscess. Cyclical pain is not common in perianal endometriosis. ${ }^{11}$

\section{Case Report}

A 37 year old female of New Delhi, India presented with perianal swelling since 10 years. There was no history of discharge, bleeding, ulceration from swelling. There was history of intermittent pain in the swelling . Swelling was oval in shape, approximately $5-6 \mathrm{cms}$ of diameter, firm in consistency, mobile and situated at right perianal area extending from 8' 0 clock to $10^{\prime} 0$ clock position. Swelling progressively increased in size. History of incision and drainage of swelling was present 3 year back. There was no history of tuberculosis. Patient had history of normal vaginal delivery with episiotomy 11 year back. Proctoscopy was normal. FNAC was done which reported stratified squamous lined tissue with ulceration with few unoriented gland in stroma (Path No 5414/15, Dept of pathology, VMMC and Safdarjung hospital, New Delhi). Investigation was not suggestive for tuberculosis. MRI Pelvis with contrast was done, which suggested T2 hypo intense lesion at right anal verge extending superiorly to involve the right external anal sphincter. The lesion is limited to right side of anal canal and advised for biopsy ( Study no 3784/24 July 2015, Dept of radiology, VMMC and Safdarjung hospital, New Delhi). Patient was prepared for excisional biopsy. Excision of perianal swelling was done with $2 \mathrm{~cm}$ margin with spared sphincter under spinal anaesthesia and sent for histopathology examination. Histopathology report was suggestive of endometriosis of perianal region (PATH NO 24/16, Dept of pathology, VMMC and Safdarjung hospital, New Delhi). Patient was followed and recurrence was noted.

\section{Discussion}

Perianal endometriosis is very rare. ${ }^{11}$ Very few number of cases reported. It is rarely $(0.2 \%$ of ectopic endometrium ) seen in the perineum where it usually localized in episiotomy scars. ${ }^{12}$ It is relatively more common in episiotomy scar where endometrial tissue gets implanted. ${ }^{12}$ In this case swelling was present at 
episiotomy scar site. Perianal swelling with cyclic pain and bleeding during menstruation may help in the diagnosis of perianal endometriosis. But these symptoms was absent in this case. FNAC may help in diagnosis . But in this case as incision and drainage was done previously at that site which may distort the site from where FNAC was taken. So it was not helpful for this cases. Anal endosonography can be done to know about anatomical location and involvement of external sphincter. ${ }^{13}$ In this case MRI had been done which had given knowledge about anatomy and sphincter involvement. Wide local excision sparing anal sphincter cures the condition and inoperable case and involvement of multiple sites may need hormonal treatment. ${ }^{12}$

\section{Conclusion}

Perianal endometriosis should be taken as differential diagnosis in female, particularly when cyclical pain is present and history of episiotomy is present. Biopsy is helpful in diagnosis.

\section{References}

[1]. Blaustein A, Kurman RJ, Blaustein 's pathology of the female genital tract. New York: Springer 2002 x, $1391 \mathrm{p}$

[2]. Rubenchik I, Auger M, Casper RF. Fine needle aspiration cytology of ovarion cysts in in vitro fertilization patients: A study of 125 cases. Diagn Cytopathol 1996: 15 :341-342.

[3]. Zanetta G, Lissoni A, Dalla Valle C, Trio D, Pittelli M, Rangoni G. Ultrasound guided aspiration of endometriosis: Possible applications and limitation. Fertil Steril $1995 ; 64: 709-713$

[4]. Leiman G, Markowitz S, Viega - Ferreira MM, Margolius KA, Endometriosis of the rectovaginal septum. Diagnosis by fine needle aspiration cytology.

[5]. Akin MR, Ho CS, Nguyen GK. Cystic endometriosis and related neoplasms arising from extragonadal endometiosis diagonsed by transvaginal fine needle aspiration biopsy. Acta Cytol 1999: 43:536-538.

[6]. Bergqvist A. Extragenital endometriosis. A review. Eur J Surg 1992;158:7-12

[7]. Michowitz M, Baratz M, Starvorovsky M. Endometriosis of umblicus. Dermatologica 1983;167:326-330

[8]. Steck WD, Helwig EW. Cutaneous endometriosis. Clin Obstet Gynecol 1966;9:373 -383

[9]. Minvielle L, De La Cruz JV. Endometriosis of the anal canal: Presentation of a case. Dis Colon Rectum 1968:11:32-35

[10]. Chatterjee SK. Scar endometriosis: A clinicopathological study of 17 cases. Obstet Gynecol 1980 :56:81-84

[11]. Schweiger W, Bacher H, Cerwenka H, Mischinger HJ: Perianal endometriosis with involvement of the external anal sphincter. Eur J Surg 1999; 165:615-617.

[12]. Marquez J, Marquez JC, Arraztoa JA et al: Extrapelvic endometriosis involving the perineum, Rev Chil Obstet Ginecol 1995 ;60:1-

[13]. Watanabe M, Kamiyama G, Uamazaki K et al : Anal endosonography in the diagonosis and management of perianal endometriosis : report of a case. Surg Today 2003; 33: 630-632. 